\title{
PARANOID SCHIZOPHRENIA -BETWEEN HYPERSEXUALITY AND SADOMASOCHISM
}

\author{
Simona Trifu ${ }^{*}{ }^{\circledR}$ (iD), Beligeanu Mihaela ${ }^{2}$, Iacob Beatrice-Ștefana ${ }^{2}$, Larimian \\ Ștefania-Parisa ${ }^{2}$ \\ *1 University of Medicine and Pharmacy "Carol Davila”, Bucharest, Romania \\ 2 Faculty of Psychology and Educational Sciences, University of Bucharest, Romania
}

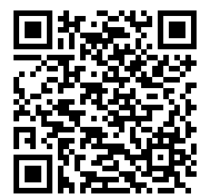

DOI: https://doi.org/10.29121/granthaalayah.v9.i3.2021.3791

Article Type: Research Article

Article Citation: Simona Trifu, Beligeanu Mihaela, Iacob BeatriceȘtefana, and Larimian ȘtefaniaParisa. (2021). PARANOID SCHIZOPHRENIA -BETWEEN HYPERSEXUALITY AND SADOMASOCHISM. International Journal of Research GRANTHAALAYAH, 9(3), 195-203. https://doi.org/10.29121/granthaa layah.v9.i3.2021.3791

Received Date: 14 March 2021

Accepted Date: 31 March 2021

\section{Keywords:}

Paranoid Schizophrenia

Discernment

Personality Disorders

Defense Mechanisms

Coping Strategies

Syndromes

Guardianship

Sexuality

Sadism

\section{ABSTRACT}

Motivation/Background: In this paper we aimed at clinically analyzing a patient diagnosed with paranoid schizophrenia, who also displays features specific to multiple personality disorders, in the context of a presentation whose key topic is sexuality. Given the global prevalence and the severity of schizophrenia, it is increasingly important to appropriately adapt and identify the patients' clinical and non-clinical personality profile. This paper also aims at making the profile of a patient diagnosed with axis I disorder ever since the age of 19, who also has got traits specific to certain personality disorders. At the same time, the work provides an interpretation of the behaviour from the psycho-dynamic point of view.

Method: The following instruments were used for performing the analysis: a clinical interview, heteroanamnesis, psychological tests, clinical course monitoring, psychodynamic interpretations, defence mechanisms identification, psychiatric observation and treatment.

Results: Based on the materials aforementioned, it has been established a possible diagnosis which includes multiple disorders: Antisocial Personality Disorder, Histrionic Personality Disorder, Schizotypal Personality Disorder, Obsessive Compulsive Personality Disorder, Cotard Syndrome, Kandinsky-Clérambault Syndrome. and there were identified defense mechanisms and coping strategies, under the influence of sexuality and sadomasochistic impulses.

Conclusions: It is highlighted the clinical picture of a patient with paranoid schizophrenia, who presents symptoms for differential diagnoses, with disorganized discourse focused on sexuality, with delusional ideation, psychotic manifestation, but also with high suggestibility, especially on the paternal line.

\section{INTRODUCTION}

\subsection{IDENTIFICATION DATA}

The patient, aged 40, single, medically retired, is living only with his father, who is also his legal guardian. The patient graduated from a prestigious high school and claims having got the highest mark (10) at the high school

(C) 2021 The Author(s). This is an open access article distributed under the terms of the Creative Commons Attribution License, which permits unrestricted use, distribution, and reproduction in any medium, provided the original author and source are credited. 
leaving examination. He was a university student of the Energetics School, but he repeated the first year 3 times. At the social-cultural and economic level, we may infer that the patient has been having a high living standard ever since the communist period, as his father owns a villa downtown Bucharest. His mother died in 2012, of lung cancer. The patient originates from a family who belonged to the upper-class during communism. He is known to be a patient diagnosed with schizophrenia and the disease onset is at about the age of 19, when he was admitted at the Predeal mental hospital. He states undergoing the fifteenth round of hospitalization at the Psychiatry Department. He thinks having undergone the military service, 'but he does not remember when he took the oath'. As far as his professional life is concerned, he was supported by his parents and worked with his father, for 6 years.

\subsection{REASONS FOR HOSPITALIZATION}

The patient came to the hospital saying at the emergency room (ER) that he had set fire to his house the day before. He came to the hospital out of his own will, not accompanied by the police. He is known for other hospitalizations at the Psychiatry Department, as well. Until the age of 40 he has totaled 15 hospitalizations here.

His clinical signs upon admission include the following symptoms: logorrhea, flight of ideas, fast speaking, the absence of logical associations, hard to follow speeches, psychomotor agitation, wide gestures, spatial-temporal disorientation, the lack of any logical support for what he is stating, tangentiality, circumstantiality, emotional flattening: he does not feel guilty for having caused the fire.

Three days prior to the incident, the patient came to us in order to get hospitalized on a voluntary basis, however the medical practitioners that examined him at the time deemed that he did not require hospitalization.

\subsection{DISEASE HISTORY}

Onset: The patient's first hospitalization was at the Predeal mental hospital, at the age of 19. He had an early onset of the disease, right after he graduated from high school. Even though he claims having got the 10 mark at the high school leaving examination and that he was a brilliant child, with vast knowledge in multiple fields, he repeated the first university year 3 times and specifies having had difficulties from the romantic relationships point of view. Until the age of 40 he has had 15 hospitalizations, his diagnosis being paranoid schizophrenia.

Ever since childhood he has been displaying 'particular sexuality' and in high school he was attracted to porn magazines and anal sex. He is a pervert, with sadomasochistic elements.

In a previous non-voluntary hospitalization, the patient displayed a bizarre behaviour, which was psychotically modified: he used the shower to get anal satisfaction, but this was more an act of self-aggressiveness, as he caused heavy hemorrhage to himself.

His father, in his capacity of legal guardian, was the one who decided whether his son should be on treatment or not, even though the physicians prescribed it each time. In the aftermath of this hospitalization, the patient came every two or three weeks, in order to get a shot of Flupentixol Depot, for two years. After this period of time, even though his symptoms improved considerably, he gave up the treatment, as his father claimed that his son's 'tushy is aching'.

The patient came to the ER three days before setting fire to the house where he was living, but he was not hospitalized at that time. For the current hospitalization, the patient came voluntarily to the ER the following day after setting fire to the house where he was living with his father. The patient displayed emotional flattening: he did not feel any guilt for the fire that he had caused, saying that he had set fire to the house because 'he did not stand the mess, as he likes spotless houses'. He also specified that the fire 'was not premeditated, but spontaneous' and that it took him two hours and a half to think about it. The investigation revealed the fact that the patient did not have any discernment when he set the house on fire.

The patient is spatially-temporally disoriented and is not able to recount moments from his life history, saying that he thinks having undergone the military service, 'but I don't remember if I took the oath'; 'I was either an officer or CIA kind of executive'. 
Simona Trifu, Beligeanu Mihaela, Iacob Beatrice-Ștefana, and Larimian Ștefania-Parisa

\section{MATERIALS AND METHODS}

There have been the following tools used in the analysis of the patient: a clinical interview, heteroanamnesis, psychological tests, monitoring of the clinical evolution, psycho dynamic interpretations, identifying the defense mechanisms, observation and psychiatric treatment.

\section{RESULTS AND DISCUSSIONS}

\subsection{PSYCHOLOGICAL EXAMINATION}

Remarks: The patient wears the proper attire for the hospital (pajama and robe). He uses ample gestures while talking. During the interview he is answering questions and he is being cooperative, although in some situations logical associations are lacking. The speech is rich, the patient has some knowledge in the psychology domain and he is bringing some personal opinions in regards to specific subjects.

Perception: The patient displays qualitative disorders of the perception, meaning hallucinations. The patient declares that he 'never ever' hears voices, but from what he says it ensures that in fact he does: 'I was hearing a voice pushing me to kill' - auditory hallucination. We can also notice preoccupations in the sexuality area, but it is hard to distinguish how much is pleasure and how much sadism. The realm of perception also includes : auditory hallucinations - 'the voice was telling me to kill a beautiful child', 'it was the angels who came and told me to set the house on fire' ; visual hallucinations - 'I saw the angels come into the house' ; pseudo hallucinations - they are not projected outside, but take place in the patient's mind, as they are not distinguished as voices clearly perceived as coming from the exterior of the patient's psychological apparatus : 'I was never hearing the voices with my ear'.

Thought: The patient has disorganization in thinking, which will be presented in the following lines. Although, based on his speech, what he says is not logically supported, the patient is striving, so he is not unwilling. Thus, both quantitative and qualitative disorders can be identified. Regarding the quantitative disorders, we remind: the acceleration of the ideational rhythm by running away from ideas: he answers tangentially to the questions, he also has a prosexic disorder, he talks a lot, he loses the connections between the associations that he makes. Regarding the qualitative disorders, there are to be mentioned: obsessive ideas: 'I wanted to commit an abominable crime - the most beautiful girl or the most beautiful boy - to end it to pieces and then to torment myself like a snake`. He claims that the idea does not belong to him, that it is foreign to him and that it comes from outside of him; delusional ideas of grandeur: he claims to have had a connection with great personalities (he mentioned well-known people such as famous actors or local celebrities), to have worked for the SRI / CIA, that he is indestructible; delusional ideas of power: the father is heterophile; delusional ideas of filiation: claims to be American; delusional erotomaniac ideas: discourse focused on sexuality; religious delusions: defines schizophrenia as `sexual desire with God`; delusional ideas of transformation and possession: he claims to have an extra chromosome that makes him indestructible and allows him not to age; delusional ideas of persecution can emerge from his metaphor related to the doll and the puppeteer, but also from his relationship with co-workers; delusional ideas of negation: he claims to be indestructible and immortal, in direct connection with Cotard syndrome; interpretation ideas: the patient looks at the world in an egocentric manner, considers that everything that happens is a reference to him: the episode when he was with his friend in the park and he felt like the world stopped for him; he believes he has the buttons that can destroy everything (and that he can push at any time), the flamethrowers; delusional ideas of influence: 'I heard some voices telling me to commit such an abominable crime, beyond reason', he claims to have an extra chromosome that explains both the reason why he doesn't look old and why he is immoral.

Speech: From the oral speech, it can be determined the delirious subtext of grandeur and symbolism `Either I was an officer, either a director for the Romanian Intelligence Service; 'We live in a world full of Puppets and Puppeteers`. Even if the speech is disorganized, the patient has a specialty language, and his vocabulary is complex, rich, offering a lot of significant details which he has taken from the books he read and the movies he watched (He thinks that they put electrons in his head). He is logorrheic, active, his speech is fast. 
Attention: Presents a slightly incapacity of focus, stability and selection of attention, he offers tangential and circumstantial answers (when he is asked if his mother was the one who got cancer, his first answer is 'yes', then 'no'; evasive answer when he is asked for the first time why he thinks he is 70 years old). The auditory hallucinations represent a key symptom of the paranoid schizophrenia, the patients being distracted by them.

Memory: The patient shows a selective hypermnesia (he does not remember enrolling into the army, but he is convinced he did, and after his affirmation he starts talking about a different subject, he is recounting his high school leaving examination; when he is asked if he has ever liked boys, he is states that they are just as innocent in front of God). Moreover, the patient presents multiple confabulatory statements: he cannot remember whether or not he enrolled in the army, but he is convinced he is an American soldier. However, he believes that his parents are not his real parents however, thus causing an emotional reversal.

Awareness of the disease: He admits the harmful effects of insomnia to his mental and physical state. He knows that the schizophrenics have auditory hallucinations in their ears, but he thinks he is special, saying 'I do not hear voices in my ears like the schizophrenics', when he is actually facing auditory pseudo hallucinations.

\subsection{POSITIVE DIAGNOSIS}

Schizophrenia is a family of diagnostics usually represented by positive symptoms (delirious ideas, hallucinations, perception disorders, bizarre behaviors) and negative symptoms (lack of normal behavior, like social distancing; lack of speech [alogia]; flattened affect; lack of motivation and initiative and/or anhedonia) (World Health Organization, 2004). The presence of schizophrenia is supported by the following negative symptoms: emotional flattening (he does not feel culpability after setting the house on fire; does not grief his mother's death, he is reliving the feel of fear that he will be next), lack of social skills, (the difficulty of involving in romantic relationships or friendships), but also by the positive symptoms): perception disorders (pseudo hallucinations and auditory hallucinations). A subtype of schizophrenia, with a late debut, characterized by delirious ideas of persecution or auditive hallucinations. Delirious ideas are typically of persecution, of grandeur or both; hallucinations are usually tied to the content of delirious fear. The cognitive function and mood are affected on a much lower level than in other forms of schizophrenia. (American Psychiatric Association, 2013). Paranoid schizophrenia is justified by the following symptoms: mental automatism (example, the fire), xenopathy: When he receives orders, not in the persuasive manner, but in an unconscious plan and he is being told what to do from outside (I was hearing some voices telling me to commit such an abomination of a crime, beyond ration'), delusion, just how it has been mentioned before and the pseudo hallucinations: 'I never heard voices in my ear'.

\subsection{DIFFERENTIAL DIAGNOSIS}

\subsubsection{KANDINSKY-CLERAMBAULT SYNDROME}

It is the psychic automatism syndrome and the core of paranoid schizophrenia. The psychic automatism syndrome is focused on the spontaneous, involuntary, 'mechanical' production of the psychic life (impressions, ideas, memories) imposed to the consciousness of the subject who loses his/her intimacy (psychic transparence) and feels guided from the outside (xenopathic phenomena) (Trifu, 2016). It is a syndrome appeared from the patient's conviction that his thoughts are no longer his own. It comprises delusional ideas of influence, pseudo hallucinations and xenopathy. The patient's symptoms are the psychic hallucinations ('I was never hearing the voices with my ear') and xenopathy (what makes the patient think those 'abominable things is a kind of SuperEgo of mine'. The patient also says that 'the world is constructed of puppets and puppeteers' and his history can metaphorically imply the fact that he is the puppet and his father is the puppeteer, because the latter one has got a very large influence upon his son. 
Simona Trifu, Beligeanu Mihaela, Iacob Beatrice-Ștefana, and Larimian Ștefania-Parisa

\subsubsection{COTARD SYNDROME}

It is a psychotic condition characterized by intense delusions of negation, enormity and immortality (I have been made indestructible by my father and mother'), the patient saying 'I was not able to feel my lung anymore', meaning that a part of the body has disintegrated or it stopped existing. (VandenBos, 2020).

\subsubsection{STRUCTURE OF PERSONALITY}

If there is proof of premorbid personality traits, then both the personality disorder and schizophrenia can exist simultaneously.

\subsubsection{ANTISOCIAL PERSONALITY DISORDER}

An example of an antisocial act of which the patient presented was to burn down his own house. The act 'was not directed, it was spontaneous`. The manifestation of the patient includes the careless ignorance regarding his own safety and others' (initially he wanted to burn down the house while his father was also inside), accompanied by the lack of guilt, remorse and empathy; emotional flattening. Besides, he's recalling without remorse how he set the house on fire 'to burn the house down, just like that', 'from the door hasta la vista, lighter on`. Moreover, the patient has aggressive phantasms: the desire to kill a small boy or girl. The fact that the patient talked about explosions and flamethrowers denotes his increased degree of danger; pyromaniac impulses. Another aspect of which the patient is confronting is the dual character (I have always been a double man, like a spy, a man with two faces, a face in the society and another face at home').

\subsubsection{HISTRIONIC PERSONALITY DISORDER}

After consulting the DSM V criteria, we found that the patient has a number of characteristics associated with Histrionic personality disorder. Each one of them will be presented, along with the appropriate example: the patient feels uncomfortable in situations where he is not in the center of attention and he has a constant need to tell stories and experiences that are out of the ordinary. Another specific aspect of this disorder is the inappropriate interaction of the individual with other people and also the inadequate behavior, which is sexual or provocative. Often, the patient has a tendency to turn his discourse into a sexualized one, often making references to these topics, even if the person he is talking to is comfortable with this or not. Moreover, he has a style of verbal expression that aims to impress the audience, but which is superficial and lacks details. The patient often quotes movies or books and compares his own life with fantastic events. Also, the way he expresses his emotions is exaggerated, theatrical and dramatic. The patient's stories are accompanied by interjections, onomatopoeias and other elements that have the role of providing impact at the level of his speech.

The individual is suggestible. Thus, the patient's father has an increased influence on him, which can result from situations such as: hiring the son in the same job as the father, the metaphor 'doll and puppeteer', the father-doctor discussion, focused on the direct influence on the patient. He misjudges relationships with those around him and considers them to be much closer than they really are. For example, the patient considers that he has a much closer relationship with the tenant who lives on the ground floor of his house than he actually had.

People diagnosed with histrionic personality disorder often tend to make uncontrolled gestures in order to receive attention. Thus, setting his own house on fire can be considered by the patient a tool to get everyone's attention. The patient tries to stand out as a moral person that has set his motives straight, claiming that if he were rich, he would donate a large part of his fortune to hospitals (Trifu, 2016).

Moreover, the patient's description of himself is exaggerated, full of grandeur: he expresses his ability to live forever compared to ordinary mortals and emphatically emphasizes that he hears voices in his head, not in his ears, contrary to what the medical staff might assume.

He can often play the role of the victim to be the center of attention: 'I never considered myself smart enough', 'I suffered like a dog that I had no girlfriend', 'When you see that you live in a mess and you will not have a sports car ... 'as he feels a constant need to be in the spotlight. 


\subsubsection{OBSESSIVE COMPULSIVE PERSONALITY DISORDER}

Obsessive-compulsive disorder is characterized by obsessions. According to DSM-V, obsessions are `Recurrent and persistent thoughts, urges, or images that are experienced, at some time during the disturbance, as intrusive and unwanted, and that in most individuals cause marked anxiety or distress'. He states the following wishes: 'I wanted to commit an abominable crime, to kill the most beautiful girl or the most beautiful boy and then to torment myself like a snake', 'I heard some voices telling me to commit such an abominable crime, beyond reason'. He mentions that these thoughts do not belong to him, that he does not recognize them as his own. The patient is aware that these ideas are not his own, that those ideas are associated with his aggression and that they physically make his life better. There is to be mentioned that at the time of the interview, the patient was already under the effect of his treatment, which played an important role in terms of awareness of obsessions. It is probable that, before medication, he wasn't aware of the effect of those intrusive thoughts and considered them as his own.

\subsection{SYMBOLIC INTERPRETATIONS}

Exploring the content and themes of hallucinations and delusional ideas is often a way to link them to the patient's past and provides valuable information about his underlying emotions. Given that delusions and hallucinations are culturally defined, it will be necessary, as in any complex assessment, to take into account the cultural context and to assess the content of delusions and hallucinations both in relation to the patient's belief system and in relationship with religious and cultural influences and context.

\subsubsection{FREUDIAN DEFENSE MECHANISM}

Displacement: Although he claims to have lung cancer, his mother is the one who was diagnosed with this disease. Out of the patient's desire to identify the reason that determined his mother's cancer, he has a theory, developed by using acausal synchronicities, through an allusive mechanism - he did an x-ray when he was admitted to psychiatry for a check-up, and in 6 months, his mother was diagnosed with cancer. In his psychotic disorganization of thought, he associated washing clothes in the hospital with the cancer's onset, so he assumed the disease was his own. This approach can also be attributed to the unconscious guilt he faces as a result of an unhealthy relationship with his mother.

Projection: he describes his colleagues as being: `sadistic', with `nervous problems` and no decision-making power, but, in fact, this can actually refer to his own attributes.

Cleavage: between the person who would like to be and the person who is (SuperEgo versus Ego).

Rationalization: he complains about the appearance of his former girlfriend, whom he calls 'grandmother'. This can be a mechanism that allows him to get over a failed relationship and to make him feel better and happier as a single man.

Regression: he is fixated in his anal stage; the regression may result from his fixation for cleaning.

Denial: mentions that he is indestructible, immortal and denies his condition.

\subsubsection{COPING MECHANISMS}

Throughout the speech, the patient described several coping methods, both functional and dysfunctional (David, 2006).

One of his coping mechanisms is to run: 'I'm running until I'm exhausted'. Moreover, even after setting his house on fire, the patient wandered around Bucharest for a while before turning himself in at the emergency room. This may indicate his intention to detach himself from his own problems, emphasizing his avoidant behavior.

On the other hand, several dysfunctional, destructive or self-destructive coping mechanisms are presented. He repeatedly mentions aggressive gestures or behaviors, some of which are coping mechanisms: 'If your wife died and you had a nuclear button that you could use, wouldn't you wipe off the whole earth? ' Moreover, he also shows selfaggressive tendencies. A representative moment for this aspect is the shower incident, when he introduced the shower head in his anus, behavior loaded with masochistic, aggressive and self-punitive tendencies. In fact, the patient repeatedly mentioned his desire to 'torment like a dog'. He often associates this desire with biblical 
Simona Trifu, Beligeanu Mihaela, Iacob Beatrice-Ștefana, and Larimian Ștefania-Parisa

characters or religious examples. Therefore, this coping mechanism is reminiscent of the religious model of punishment for the forgiveness of the sin.

\subsubsection{PYROMANIA}

Although the reason for hospitalization is setting his house on fire, the patient does not have criteria for diagnosis under the spectrum of pyromania, according to DSM-V. Instead, the decision to set his house on fire rather refers to a dysfunctional coping mechanism of the patient who, overwhelmed by the negative feelings in his own house, in a cathartic gesture, decides to set it on fire. Moreover, the place where the fire starts is the bed itself, the source of all the patient's mental suffering. Along with the flames, there is a spiritual cleansing of 'misery', both physical and mental, which obsesses the patient and occupies the whole spectrum of thought, which produces a disorganization of associations and attacks his contact with reality.

\subsubsection{SADOMASOCHISM}

Sadism is a personality trait. This is part, along with Psychopathy, Machiavellianism and Narcissism, of the extended version of the Dark Trade (Međedović\&Petrović, 2015). Therefore, sadism is a personality trait with negative valence, often observed in the patient's speech. He takes pleasure in hurting others, repeatedly mentioning his desire to commit 'an abominable crime`. Moreover, he repeatedly emphasizes that the subjects of his aggression would be 'the most beautiful girl or the most beautiful boy`. This delusional idea is recurrent in the patient's discourse and, although in the past it was considered that sadistic fantasies are rare in schizophrenic patients, there is a higher prevalence (Smith, 1999).

Masochistic behavior refers to a number of models of self-destructiveness or self-harm, without suicidal intent (McWilliams, 2011). For example, the patient inserts the shower head in the anus. His goal is not self-satisfaction, but self-aggression. Moreover, during the interview, the patient repeatedly emphasizes phrases related to torment and suffering: 'I suffered like a dog', 'to torment me like a snake'. It is unclear what is the source of the patient's masochistic desires, but it seems that his aggressive tendencies were only directed towards himself, even if in the imaginary spectrum the aggression is directed towards others. One hypothesis would be that the patient wants to go through suffering, even self-caused, to deal with his problems, in the form of a dysfunctional coping mechanism. Another option would be that he obtains a state of well-being by being in torturous situations. In fact, the masochism could be a veiled expression of strategically oriented aggression to avoid hetero-aggression. Identifying the reason for the patient's masochistic desires and behaviors is necessary to perform a therapeutic intervention in order to reduce the negative consequences of the patient's aggression.

\subsubsection{THE EGO CONFLICTED BY SUPEREGO}

One of the most important parts of the patient's discourse is the conflict between SuperEgo and Ego, Freudian structures developed in early childhood, under the influence of parental figures (Gabbard, 2014). There is an internal conflict, between low self-confidence and the superiority he displays, along with his defiant attitude, which refer to omnipotence. Throughout the speech, the patient mentions multiple delusional ideas of grandeur that may refer to surreal expectations of reality. He mentions the desire to have a sports car, a big and clean house and makes multiple references to the desire for a perfect life. There is a conflict between the rigid SuperEgo and the mediocre Ego, which the patient cannot manage. Thus, he creates his own fantastic reality, through his delusional idea of grandiose and filiation: he claims to be American, associates with great personalities of the time, mentions that he works for the secret services, etc. This conflict between SuperEgo and Ego also resides in the multiple mentions to his father, whom he feels he cannot compare to. He is stuck in the position of a schizophrenic son who has barely graduated from college and has not worked for more than 6 years. He is a prisoner of his constant mental deterioration and is under the continuous paternal influence, who guides even his medical path. Throughout his life, the father, being a nomenclaturist, tried to offer his son the same professional path. Due to the onset of the disease, however, the patient was unable to meet the father's standards, which created a strong conflict between the two. Moreover, the SuperEgo seems to offer even an internalized image of the paternal figure which, being unattainable for the son, contributes to his anguish and mental suffering. 


\subsubsection{THE WORLD IS CONSTRUCTED OF PUPPETS AND PUPPETEERS}

This symbolic sentence can metaphorically imply the fact that the patient is the puppet, namely the object of the manipulation, and the puppeteer is outside, he is a force that controls him. We can metaphorically think that the puppeteer may even be his father. The father is the patient's companion and he has had a significant impact upon his subsequent development. It was him who had him hired in the same place where he was working, too, and it is still him who interrupted the patient's treatment. The absence of the mother is felt in the patient's life, so the father is his only attachment figure. He cannot reach his father's standards and he has got a psychotically modified behaviour, thinking that 'he has got American blood' and that 'he is indestructible'. The father had knowledge of his suggestibility and it is possible that he may voluntarily or involuntarily suggested to him to set fire to the house in order to receive an amount of money from the insurance company. This is not for sure, but the certain thing is that the father has got a great deal of influence upon the patient.

\subsection{WHAT IS PARTICULAR?}

His act of setting the house on fire is considered an element of a quasi-psychotic episode because he does not support the idea that he was urged from the outside to put the act together (the exclusion of xenopathy and the delusion of influence), although he is stating that he burned the house down because it was dirty. It was concluded that the patient was lacking judgement when he put the act together. The fact that he presented himself before and after the fire to the hospital voluntarily proves that he was conscious, but he performed the act indiscriminately, being so suggestive, it is possible that he misinterpreted allusively a conversation between him and his father, which had some form of influence over him. The speech thematic of the patient is oriented towards the sadomasochistic sexuality aspect: anal sex tendencies (the shower incident, the erotic pleasures from his teens with his first sexual partner). Moreover, he is associating schizophrenia with the sexual desire with God, the Father.

\section{CONCLUSIONS \& RECOMMENDATIONS}

\subsection{EVOLUTION, PROGNOSIS, RECOMMENDATIONS, DISCUSSIONS}

Given that there is no clear chronology of the patient's symptoms, it cannot be specified exactly whether the schizotypal personality disorder (Predescu, 1989) is a premorbid diagnosis, prior to the onset of schizophrenia. Therefore, the following criteria specific to this disorder will be mentioned, in case the patient matches it: poor social and interpersonal relationships - 'I suffered for so many years watching movies alone', acute discomfort and reduced ability to develop close relationships - 'when I was a child I suffered like a dog that I could have a girlfriend', cognitive distortions- lived the feeling of 'deja-vu', had a premonition that he will be the next member of the family who will suffer from cancer, explaining his conviction: 'I know this is how it's going to be, but I cannot explain why' and with perceptual distortions such as hallucinations and pseudo-hallucinations.

Regarding the prognosis, there is a fine line that differentiates a positive evolution of the disease from a negative one. On the one hand, we can talk about a negative evolution, based on the tense family climate, poor coping mechanisms, repeated discontinuation or refusal of treatment, but also the patient's suggestibility in front of his own father. On the other hand, there may be a positive evolution supported by disease awareness and IQ, which seems to be high.

\subsection{TREATMENT}

In the aftermath of the patient's latest hospitalization, a shot of Flupentixol Depot was given to him every twothree weeks. He followed the treatment for two years and his symptoms improved considerably. After this time frame, the patient gave up the treatment, because of the fact that his father refused to take him to the hospital for the administration. Flupentixol belongs to a group of medicines called neuroleptics. It acts upon the nervous ways, in specific areas of the brain, and it helps correcting the lack of balance of certain chemical substances at the level of the brain, which cause the symptoms of the disease. By supporting the patient's father to have a better relationship 
with his son, the latter one can adapt himself better to social life and the symptoms improvement process can be accelerated and better upheld thanks to the direct contribution of the people close to him (Schaffer \&Rodolfa, 2019).

\subsection{CONCLUSIONS}

Whereas in the recovery of patients with schizophrenia, the relationship with the family is of crucial importance, the support of the father in the relationship with his son is highly recommended. Thereby a mediation between them could take place and transform a tensioned and destructive relationship into a beneficial and healthy one. Moreover, this relationship will support the recovery path of the patient (Lidz\&Lidz 1949). Given the responsiveness to the treatment, the only factor that can positively influence the patient's prognosis is the familial relationship, especially in the context of which the patient represented a high degree of suggestibility, which results from his behavior in relation with the paternal influence.

\section{SOURCES OF FUNDING}

This research received no specific grant from any funding agency in the public, commercial, or not-for-profit sectors.

\section{CONFLICT OF INTEREST}

The author have declared that no competing interests exist.

\section{ACKNOWLEDGMENT}

None.

\section{REFERENCES}

[1] American Psychiatric Association. (2014). Diagnostic and statistical manual of mental disorders (5th ed., Text rev.). Washington, DC: Author.

[2] David, D. (2006). Tratat de psihoterapii cognitive și comportamentale. Polirom.

[3] Gabbard, G. O. (2014). Psychodynamic psychiatry in clinical practice. American Psychiatric Pub.

[4] Lidz, R. W., \&Lidz, T. (1949). The family environment of schizophrenic patients. American Journal of Psychiatry, 106(5), 332-345.

[5] McWilliams, N. (2011). Psychoanalytic diagnosis: Understanding personality structure in the clinical process. Guilford Press.

[6] Međedović, J., \&Petrović, B. (2015). The dark tetrad. Journal of Individual Differences.

[7] Predescu, V. (1989). Psychiatry - Volume 1. EdituraMedicală.

[8] Schaffer, J., B., Rodolfa, E. (2018). An ICD-10-CM Casebook and Workbook for Students: Psychological and Behavioral Conditions. Washington, DC: American Psychological Association

[9] Smith, A. D. (1999). Aggressive sexual fantasy in men with schizophrenia who commit contact sex offences against women.The Journal of Forensic Psychiatry, 10(3), 538-552.

[10] Trifu S. (2016). Diagnostic procedural diagram in medical psychiatric approach. Saarbrucken: LAP Lambert Academic Publishing.

[11] [VandenBos, G., R. (2015). APA dictionary of psychology. Washington, DC: American Psychological Association

[12] World Health Organization. (2004). ICD-10: international statistical classification of diseases and related health problems: tenth revision, 2nd ed. World Health Organization. 